\title{
Differential Diagnosis of Calvarial Tumors: A Series of 8 Cases
}

\author{
Jitesh Kumar Sharma ${ }^{1}$ Rashim Kataria ${ }^{1}$ Madhur Choudhary ${ }^{1}$ Devendra Kumar Purohit ${ }^{1}$ \\ ${ }^{1}$ Department of Neurosurgery, SMS Medical College, Jaipur, \\ Address for correspondence Devendra Kumar Purohit, MS, Mch, \\ Rajasthan, India \\ Department of Neurosurgery, SMS Medical College, Jaipur 302004, \\ Rajasthan, India (e-mail: devendrapurohit@rediffmail.com).
}

Indian J Neurosurg 2022;11:140-146

\begin{abstract}
Introduction To present and discuss the clinical presentations, investigations, and treatment options for skull bone tumors.

Materials and Methods This study was conducted from January 2019 to December 2019 at the Department of Neurosurgery. During this period, eight patients presented with skull bone tumor in the outpatient department. All patients were thoroughly investigated. Surgery was conducted on six patients and two patients had disseminated carcinoma; hence, surgery was not done. Patients were regularly followed-up after the surgery.

Results In our study, out of eight cases, five were females and three were males. We had two cases of fibrous dysplasia, two cases of osteomas, and one case each of brown tumor, metastases from lung carcinoma, metastases from follicular carcinoma of thyroid, and Ewing sarcoma/primitive neuroectodermal tumor (PNET). Excision of tumor

\section{Keywords}

- skull tumors

- benign skull tumor

- malignant skull tumors was performed where indicated and adjuvant chemo- and radiotherapy was suggested wherever required.

Conclusion Bony tumors of the skull are uncommon diseases for the neurosurgeons. These tumors require a careful diagnosis with suitable radiological examinations and proper clinical correlation for proper management.
\end{abstract}

\section{Introduction}

Skull tumors are uncommon lesions, making up $<2 \%$ of all the musculoskeletal tumors. ${ }^{1}$ They presented with skull mass, with or without pain, and with or without neurological symptoms. Skull bone tumors have complex regional anatomical features and require interdisciplinary therapy. Hence, understanding the differentiation and identifying the type of tumor is still a clinical challenge.

The World Health organization (WHO) divided skull tumors into the following three different categories: benign, malignant, and undefined neoplastic nature tumors (UNNT). ${ }^{2,3}$ Among these three, malignant are the most common skull tumors. On the basis of primary proliferating cells, benign skull tumors can be cartilage-forming, bone-forming, tumor of blood or blood vessels, tumor of connective tissues, Paget disease, or epidermoid, dermoid, or aneurysmal bone cysts. In radiography, benign tumors usually indicated as well-defined borders with a narrow transition zone and sclerotic margins. Among the above-mentioned benign skull tumors, osteomas are the most common bone forming brain tumors. Osteomas mostly occur in the frontal bone of the skull. Osteomas on CT image give the impression of round sclerotic lesions, arising from the outer table of the skull without involvement of diploë. ${ }^{4}$ The second most common benign skull tumor is hemangioma. As the name suggests, hemangiomas are tumors of blood or blood vessel origin, comprise published online May 25, 2021
DOI https://doi.org/

$10.1055 / \mathrm{s}-0041-1722828$ ISSN 2277-954X.
(C) 2021. Neurological Surgeons' Society of India.

This is an open access article published by Thieme under the terms of the Creative Commons Attribution-NonDerivative-NonCommercial-License, permitting copying and reproduction so long as the original work is given appropriate credit. Contents may not be used for commercial purposes, or adapted, remixed, transformed or built upon. (https://creativecommons.org/licenses/by-nc-nd/4.0/).

Thieme Medical and Scientific Publishers Pvt. Ltd. A-12, 2nd Floor, Sector 2, Noida-201301 UP, India 
approximately $10 \%$ of benign skull tumors and usually occur in adults (4th to 6th decade). ${ }^{5}$ In CT scans, hemangiomas appear as trabeculae, sunburst pattern. Surgical resection is the prevalent common treatment for all benign tumors. Another calvarial tumor is fibrous dysplasia. It mostly occurs among young individuals and is formed through replacement of normal bone by immature woven bone. It appears as an intradiploic, expansive lesion with the characteristic "ground-glass matrix" in the CT scan. ${ }^{6.7}$ Frontal and temporal bones are the preferential locations for fibrous dysplasia, which may cross sutures. Surgical interventions are required in case of severe mass effect. ${ }^{4}$

Among malignant skull tumors, metastases are the most common malignant tumors in adults (above age of 50). Metastases are usually secondary to adult breast, lung, prostate, renal and thyroid cancer and to children's neuroblastomas or sarcomas. ${ }^{8}$ Metastases typically manifest as several osteolytic lesions that spread into adjacent tissues with a soft-tissue element. In malignant skull tumors, margins are poorly defined, having a wide transition zone, aggressive periosteal reaction, and often have a soft tissue component. These lesions cause dramatic, intracranial or extracranial destruction. ${ }^{9}$ When single and expanded osteolytic lesions are encountered, metastasis from thyroid or renal neoplasm should be suspected. Sclerotic metastases are seen in prostate cancer. ${ }^{9}$ Other malignant tumors include osteogenic sarcoma, chondrosarcoma, multiple myelomas, and chordoma. Hence, due to varying histopathology of these skull tumors, a detailed understanding of these tumors is required. We therefore, conducted this case series on skull tumors, analyzing their clinical, pathology, and radiographical features.

\section{Materials and Methods}

This prospective study was conducted on eight patients admitted with skull tumors at the Department of Neurosurgery during January 2019 to December 2019. The patients were incorporated in the study after obtaining an informed and written consent. Patients of all age group were included in the study. Initial examination in the form of CT and MRI was suggested to all patients. Clinical parameters, including age, sex, and tumor location, were noted. Surgery or excision of tumor was planned according to the site and condition of tumor.

\section{Result}

Patients of all age groups were included in the study. Among eight cases, three were males and the rest were females. Majority of the patients were adults in our study. Herein, we found two cases of fibrous dysplasia, two cases of osteomas, and one case each of brown tumor, metastases from lung carcinoma, Ewing sarcoma/primitive neuroectodermal tumor (PNET), and metastases from follicular carcinoma of thyroid. The summary of all the cases is given in - Table 1 .

Among eight cases, four cases presented with painful swelling, whereas rest four cases presented with painless swelling. It comprises fibrous dysplasia, metastases from thyroid follicular carcinoma, and metastases from lung carcinoma. Left frontal bone was the most frequent location, with predominately benign tumors. In our study, the most common benign tumors were osteomas. Giant cell tumor (GCT) was the only tumor with intermediate malignant potential. Illustrated detailing of tumors is provided in the next section.

Table 1 Summary of lesions

\begin{tabular}{|l|l|l|l|l|l|l|l|}
\hline $\begin{array}{l}\text { S } \\
\text { No. }\end{array}$ & Age & Sex & Location & Symptoms & Management & Diagnosis & Type of tumor \\
\hline 1 & 23 & F & Left frontal bone & Pain, swelling & Surgical excision & Osteoma & Benign \\
\hline 2 & 52 & M & $\begin{array}{l}\text { Midline forehead } \\
\text { frontal region }\end{array}$ & Headache & Surgical excision & Brown tumor & Benign \\
\hline 3 & 20 & M & Left frontal bone & Painless swelling & $\begin{array}{l}\text { Surgical excision + } \\
\text { cranioplasty }\end{array}$ & Fibrous dysplasia & UNNT \\
\hline 4 & 60 & F & $\begin{array}{l}\text { Midline forehead } \\
\text { frontal region }\end{array}$ & Painless swelling & $\begin{array}{l}\text { Radiotherapy + } \\
\text { chemotherapy }\end{array}$ & $\begin{array}{l}\text { Metastases from } \\
\text { lung carcinoma }\end{array}$ & Malignant \\
\hline 5 & 38 & F & $\begin{array}{l}\text { Right occipital bone } \\
\text { headache }\end{array}$ & $\begin{array}{l}\text { Fungating mass, } \\
\text { Radiotherapy + } \\
\text { chemotherapy }\end{array}$ & $\begin{array}{l}\text { Ewing's sarcoma/ } \\
\text { PNET }\end{array}$ & Malignant \\
\hline 6 & 50 & F & Right occipital bone & Painless swelling & $\begin{array}{l}\text { Surgical excision } \\
+ \text { Radiotherapy } \\
\text { +/-chemotherapy }\end{array}$ & $\begin{array}{l}\text { Metastases from } \\
\text { thyroid follicular } \\
\text { carcinoma }\end{array}$ & Malignant \\
\hline 7 & 16 & M & Left frontal bone & Painless swelling & $\begin{array}{l}\text { Surgical excision + } \\
\text { cranioplasty }\end{array}$ & Fibrous dysplasia & UNNT \\
\hline 8 & 18 & F & Left Frontal bone & Pain, swelling & Surgical excision & Osteoma & Benign \\
\hline
\end{tabular}

Abbreviations: PNET, primitive neuroectodermal tumor; UNNT, undefined neoplastic nature tumor. 
Two patients underwent cranioplasty after surgery. In the case of metastases, after surgical removal of head tumor, chemotherapy and radiotherapy were given to the patients as further management. Two patients had disseminated cancer, so only biopsy/fine needle aspiration cytology (FNAC) was performed and radiotherapy and chemotherapy were given.

\section{Discussion}

Calvarial tumors of the skull are rare lesions; therefore, they have not been systematically investigated in literature. With the advancement of radiographical techniques, study of calvarial tumors become approachable.

\section{Osteomas}

Osteomas are slow-growing benign tumors majorly arising in the craniofacial region. We encountered two cases of osteomas. Both patients were females (of age 18 and 23 years) and admitted with complaints of of dull aching pain and swelling over left frontal region since 2 and 1.5 years, respectively. The patients were evaluated and diagnosed as a case of frontal bone swelling (as shown in - Fig. 1). CT head suggested expansile lesion in left frontal bone, with no evidence of surrounding soft tissue and no intraparenchymal abnormality. Surgery was performed and total excision of lesion done. Histopathology was suggestive of fibroblastic cells with bony sclerosis. Herein, during follow-up, no recurrence of lesion was seen in surgically excised tumor. The survival rate is $100 \%$ in our cases.

Osteomas are noncancerous, slowly growing fibrous tumors with small osteoid or osseous spicules embedded in proliferating connective tissues. ${ }^{10,11}$ According to literature, the most common site for osteoma is the frontoethmoidal region. ${ }^{12}$ Peak incidence of these tumors is 10 to 30 years. These lesions are generally formed in outer table, and inner table remains intact. A head CT of osteomas show homogenous, well-defined, sclerotic lesions. Osteomas are 100\% treatable by surgery. Similar to osteomas, osteoblastoma is a relatively rare benign tumor, having similar histopathology to osteoid osteomas. In comparison to osteomas, osteoblastomas are relatively larger and possess more fibrous stroma,

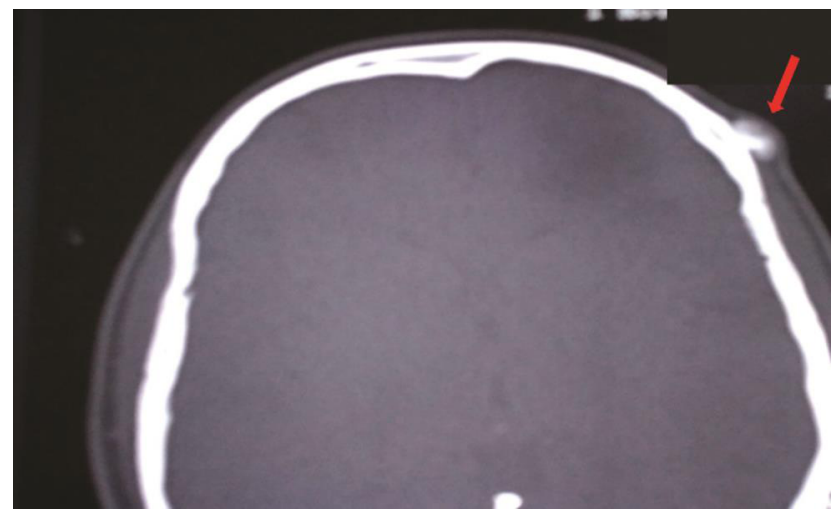

Fig. 1 Osteomas CT axial head image showing juxtacortical sclerotic lesion along the outer table of left frontal bone (as indicated by arrow). many multinucleated giant cells, extravasated blood, and less osteoid. ${ }^{13}$

\section{Brown Tumor}

Giant cell tumors (GCT) are one of the rare lesions of skull, which ascend from the nonosteogenic stromal cells of bone marrow. ${ }^{14}$ In our study, we encountered a 52-year-old male admitted with chief complaint of swelling associated with headache over forehead region since 6 months. Patient was evaluated and MRI along with CT head was done, which suggested expansile lobulated lesion of frontal bone, causing erosion of both outer and inner table with expansion of bone which, in turn, caused mass effect bifrontal lobes. The head MRI and CT is shown in - Fig. 2A, B respectively. USG neck was suggestive of right parathyroid mass. Patient showed hyperparathyroidism with parathyroid hormone (PTH) levels $>2000 \mathrm{pg} / \mathrm{mL}$, elevated serum calcium levels (14.56 mg/ dl) along with elevated alkaline phosphate values (559 IU/L) and normal serum phosphorus levels (3.55 mg/dl). Surgery was planned and gross total excision of bony swelling done. Histopathology was suggestive of giant cell lesion. As patient is afflicted with hyperparathyroidism, brown tumor was also suggested. The patient was referred to endocrinology for further management. During follow-up, no recurrence of lesion seen in surgically excised tumor.

Brown tumor is a benign osseous lesion associated mainly with hyperparathyroidism. ${ }^{15}$ The tumor majorly occurs in medullary shaft of long bones and can be multifocal or solitary. ${ }^{16}$ Brown tumor is a localized accumulation of fibrous tissue and giant cells which can replace bone and cause bone expansion. Brown tumors are generally well-defined unilocular or multilocular pure lytic lesions, which stimulate little reactive bone formation. The pathologically equivalent giant cell tumors mostly have indistinguishable boundaries and blend into the bone, a finding which can be used to differentiate them from brown tumors. Brown tumor is usually associated with elevated serum calcium levels and alkaline phosphate and low level of serum phosphate. ${ }^{17}$ For successful management of brown tumor, reducing the PTH levels is significant. Surgical treatment, including removal of parathyroid mass, could be effective. Bisphosphonates can be recommended for normalizing serum calcium levels. ${ }^{18}$

\section{Fibrous Dysplasia}

Fibrous dysplasia is a rare bone disorder in which lesion (fibrous) tissue develops in place of normal tissue. In our study, we encountered two patients of fibrous dysplasia. Both patients were male of ages 20 and 36 years, respectively. They were admitted with complaints of painless swelling in left frontal bone. CT head of both patients suggested thickening and expansion of left frontal bone, with no evidence of surrounding soft tissue and no intraparenchymal lesion seen, as shown in - Fig. 3. In one case, asymmetry of lateral ventricle is seen. Surgery was performed and complete excision of swelling done, followed by cranioplasty. Histopathology was suggestive of fibrous dysplasia. No recurrence of lesion was seen in surgically excised tumor during follow-up. 

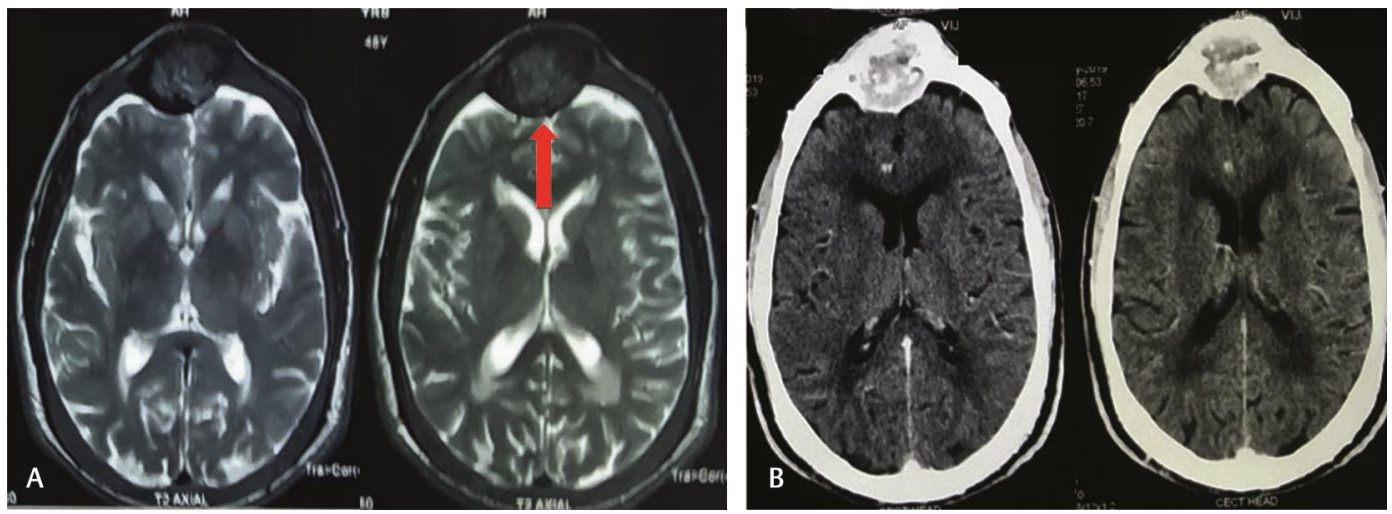

Fig. 2 Brown tumor. (A) T2-weighted MRI axial image showing expansible lobulated lesion over frontal bone, causing indentation over bifrontal bone. (b) Head CT axial image showing erosion of outer and inner table with bony expansion.
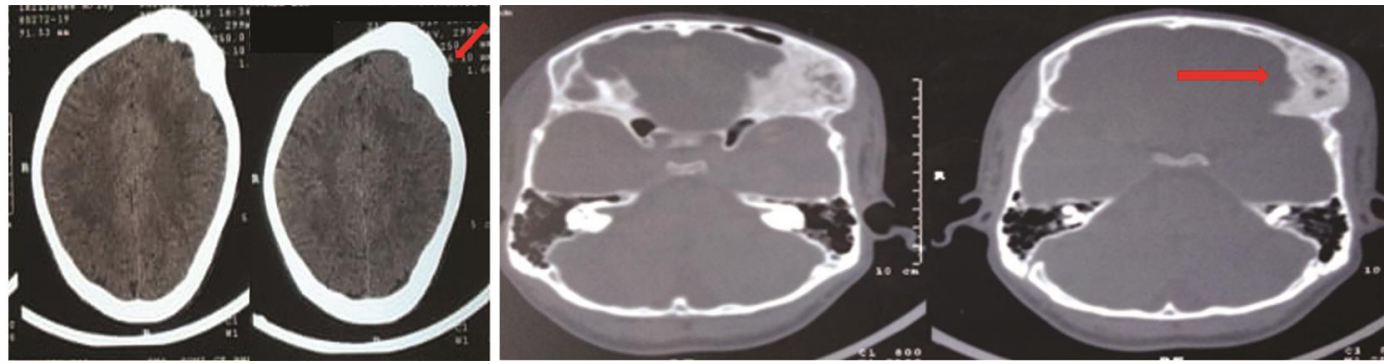

Fig. 3 Fibrous dysplasia. Axial CT head image showing thickening and expansion of left frontal bone.

Fibrous dysplasia is often characterized by replacement of normal bone by immature woven bone hence, weakening the bone. ${ }^{4}$ Fibrous dysplasia mainly occurs in childhood and young age (10-30 years). Generally, it is asymptomatic and painless, but due to mass enhancement, sometimes it shows symptoms on account of increased mass. These tumors are majorly found in frontal and temporal bones. In a study by Leeds, ${ }^{19} 46$ patients having fibrous dysplasia were studied. The most common symptom of this tumor is asymmetry of skull and facial bone. Although the etiology is still not clear, the molecular biology suggests a mutation in the Gs $\alpha$ subunit and activation of c-fos and other proto-oncogenes. ${ }^{20}$

\section{Metastatic Tumors}

Metastases to the calvarium is common (15-25\%) in cancer patients. The most common metastases occur from breast cancer, followed by lung, prostate and lymphoma. Metastases from thyroid is not common in literature. ${ }^{21}$ Follicular subtype is most common in metastases from the thyroid carcinomas. In our study, a 50-year-old female presented with gradually progressive painless swelling over right occipital region since 1 year. CT head suggested heterogeneous enhancing soft tissue density mass with calcific foci ( $\neg$ Fig. 4 A), causing bony destruction of occipital bone on right side along with extracranial extension, as illustrated in $\mathbf{- F i g}$. 4B. On further evaluation, ultrasonography neck suggested hypoechoic lesion in right thyroid lobe. The patient underwent surgery and wide local excision of swelling with extracranial part was done. Histopathology showed presence of varied sizes of thyroid follicles, with nuclear atypia and focal presence of colloid.
Overall, it favors metastases from thyroid follicular carcinoma. The patient had undergone total thyroidectomy and completed postoperative radiotherapy. Similar observations were found by other researchers also where skull metastases from thyroid follicular carcinoma occurred. ${ }^{22-24}$ Literature and our observations suggest that these tumors are more common in females compared with males. The most favorable site for these tumors is midline of the frontal and parietooccipital region. ${ }^{21}$

In another case, a 60-year-old female presented with painless swelling over forehead region for 2 months. CT head suggested destructive soft tissue density lesion with calcification in frontal bone glabela and forehead region, with erosion of frontal bone causing metastases, as demonstrated in -Fig. 5. On further investigation, CT thorax and abdomen showed a malignant mass, with spiculated margins seen in left lung upper lobe along with foci of calcification and multiple enlarged lymph nodes seen in prevascular, pre, and paratracheal region with liver and adrenal metastasis. USG-guided FNAC of frontal region mass suggested poorly differentiated malignant neoplasm. Overall diagnosis suggests metastases from lung carcinoma. The patient survived only for 2 months after referral and had not completed the chemotherapy regime. Bone metastases from lung cancer is too common in advanced lung cancers. ${ }^{25}$ Approximately, 30 to $40 \%$ lung cancer patients show metastases to bone. Lung cancer cells spread either through the bloodstream or through the lymphatics to the brain. After breast cancer, lung cancer is the most common cancer that spreads to the brain. Approximately, 25\% lung 
cancer patients develop metastases to the brain during the course of illness. Komatsu et $\mathrm{al}^{26}$ investigated 70 patients with brain metastases from histologically confirmed lung cancer. The type was subdivided into three categories: adenocarcinoma, small-cell lung carcinoma (SCLC), and other nonsmall cell lung cancer (NSCLC). Turner et al. ${ }^{27}$ encountered a rare case of lung cancer metastases with a solitary skull metastasis. D’Antonio et $\mathrm{al}^{25}$ presented a review, explaining the recent advances in therapeutic strategies in bone and brain metastases in lung cancer. Surgery, irradiation, stereotactic radiosurgery, and chemotherapy can be used to treat patients with such kind of tumors.

Osteosarcoma is malignant skull tumor in which tumor cell produce osteoid or immature bone. ${ }^{28}$ As much as 5 to $10 \%$ of osteosarcomas are from lung metastases, and imaging of chest should be done. Chemotherapy is required along with surgery in the treatment of these tumors. Multiple myelomas are another common malignant bone neoplasm in adults. Multiple myelomas (tumor of plasma cells) can be defined as bone marrow disorder characterized by monoclonal proliferation of plasma cells. ${ }^{29}$ It mainly occurs in adults (above 40 years age). In CT scans, it appears as "punched out osteolytic lesions."

\section{Ewing's Sarcoma}

Peripheral PNET, also known as Ewing sarcoma, show varying degrees of neuroectodermal differentiation. ${ }^{30}$ In an another case, we encountered a 42-year-old female, who presented with gradually progressive fungating swelling (see - Fig. 6A) and dull aching pain in midline occipital region since 30 days. Head CT shows large heterogeneously enhancing soft tissue density mass lesion in occipital region, with involvement of cutaneous-subcutaneous planes and erosive destruction of bony occiput, and extension to right paramedian parieto-occipital lobe, as shown in - Fig. 6B. On further evaluation, CT chest and abdomen showed diffuse pulmonary metastasis with bilateral adrenal and bilateral adnexal involvement, and lytic lesion in both femoral head and acetabulum. This probably suggests aggressive malignant mass lesion. Histopathology findings suggest primitive PNET/Ewing's sarcoma. Chemotherapy was suggested to the patient for 3 months for initial follow-up. Ewing's sarcoma is highly malignant bone tumor, commonly affecting the long bones and the pelvis. It is more prevalent in young adults and in children. ${ }^{31,32}$ It is more prevalent in frontal and parietal convexities. ${ }^{33}$ These tumors can be characterized by small round blue cells sheets with an increased nucleus-to-cytoplasm ratio. ${ }^{34}$ Tumor cell membranes normally express CD99 and vimentin. ${ }^{35}$ In CT, an "onion-peel" arrangement with layers of bone mottling and erosion, as well as new bone formation, can be found..$^{36}$ Surgical removal of the tumor can be done followed by radiotherapy and chemotherapy, all of which are essential. Prognosis of Ewing sarcoma is poor-to-moderate, depending on condition and follow-up treatment. ${ }^{31,36}$

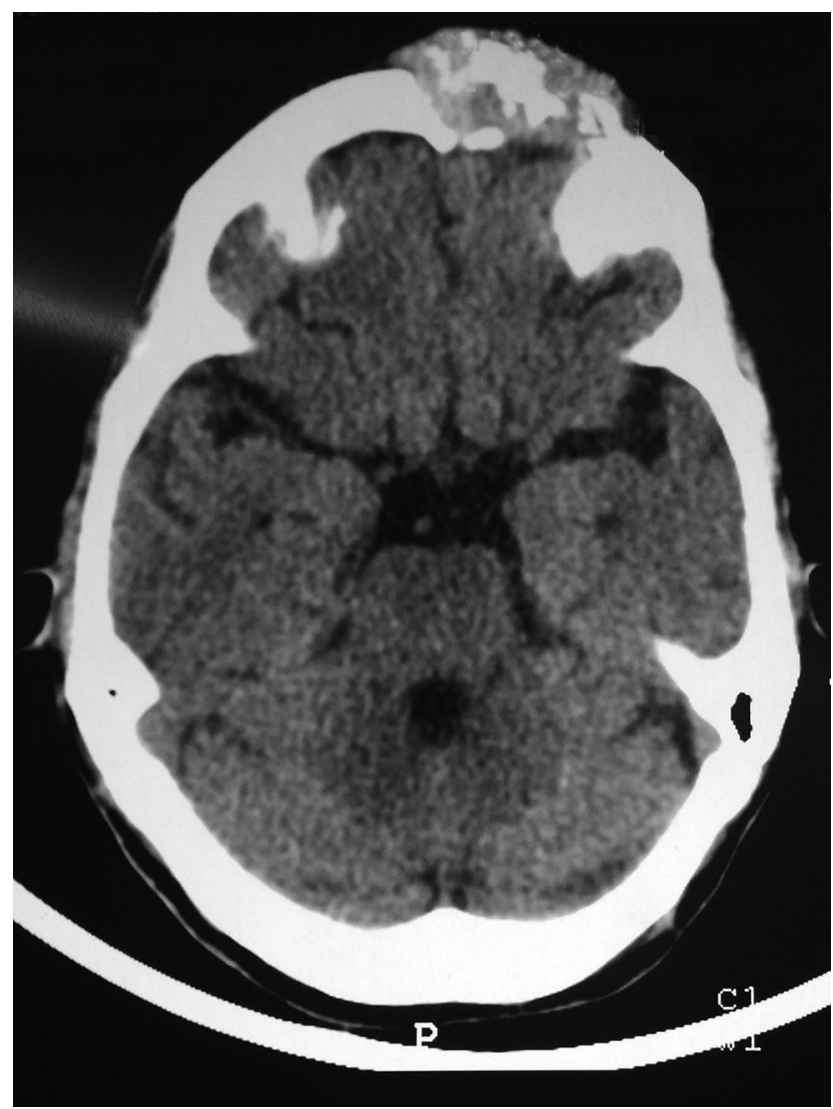

Fig. 5 Metastases of lung carcinoma. Head CT suggestive of destructive soft-tissue density lesion with calcification in frontal bone glabela.
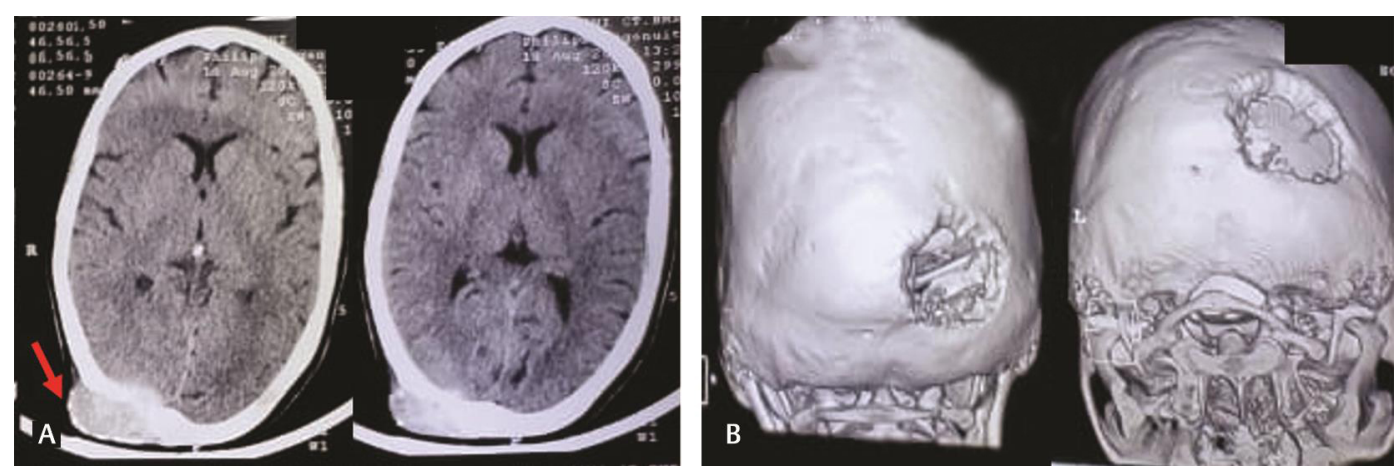

Fig. 4 Metastases from follicular carcinoma of thyroid. (A) Head CT showing soft tissue with calcified foci and (B) bony destruction of right occipital bone (as indicated by arrow). 

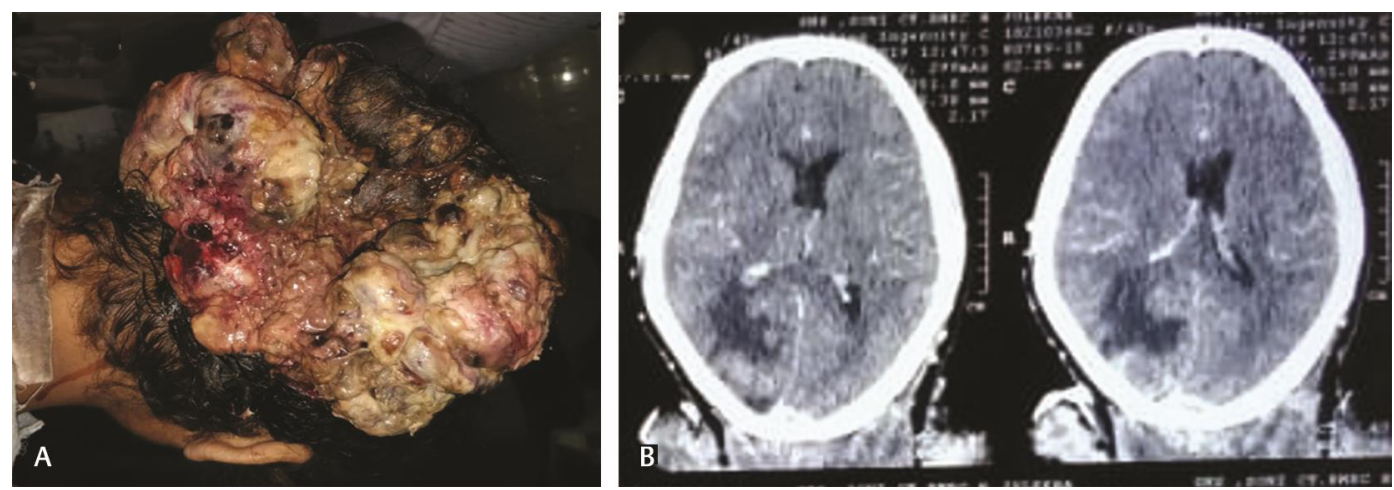

Fig. 6 Ewing sarcoma. (A) Fungating lesion over scalp in occipital region and (B) Head CT axial image showing lesion over occipital region, with erosive destruction of bony occiput.

\section{Conclusion}

Skull tumor can be categorized into benign, malignant, and undefined neoplastic nature tumors (UNNT). Skull tumors require a careful diagnostic, suitable radiological examinations, and proper clinical correlation to establish a correct diagnosis and treatment procedure. In the case of malignant tumors, chemo- and radiotherapy are further suggested to the patients. Postoperative follow-up is suggested in all the cases. Further management and quality of life of the patient is dependent on the histopathological diagnosis.

\section{Conflict of Interest}

None declared.

\section{References}

1 Liu H, Zhang X, Zhang M, et al. Skull bone tumor: a review of clinicopathological and neuroimaging characteristics of 426 cases at a single center. Cancer Commun (Lond) 2019;39(1):8

2 Bovée JVMG. Molecular pathology of bone tumors: what have we learned and how does it affect daily practice? Surg Pathol Clin 2017;10(3):xiii-xiv

3 Fletcher CDM, Bridge JA, Hogendoorn P, Mertens F. WHO Classification of Tumours of Soft Tissue and Bone. 4th ed. Lyon, France: WHO Press; 2013:468

4 Colas L, Caron S, Cotten A. Skull vault lesions: a review. Am J Roentgenol 2015;205(4):840-847

5 Thomas JE, Baker HLJr. Assessment of roentgenographic lucencies of the skull: a systematic approach. Neurology 1975;25(2):99-106

6 Chong VFH, Khoo JBK, Fan Y-F. Fibrous dysplasia involving the base of the skull. Am J Roentgenol 2002;178(3):717-720

7 Lustig LR, Holliday MJ, McCarthy EF, Nager GT. Fibrous dysplasia involving the skull base and temporal bone. Arch Otolaryngol Head Neck Surg 2001;127(10):1239-1247

8 Gangadhar K, Santhosh D. Radiopathological evaluation of primary malignant skull tumors: a review. Clin Neurol Neurosurg 2012;114(7):833-839

9 Gomez CK, Schiffman SR, Bhatt AA. Radiological review of skull lesions. Insights Imaging 2018;9(5):857-882

10 Geschickter CF. Primary tumors of the cranial bones. Am J Cancer 1936;26:155

11 Yudoyono F, Sidabutar R, Dahlan RH, Gill AS, Ompusunggu SE, Arifin MZ. Surgical management of giant skull osteomas. Asian J Neurosurg 2017;12(3):408-411

12 Sente M, Topolac R, Peić-Gavran K, Aleksov G. [Frontal sinus osteoma as a cause of purulent meningitis]. Med Pregl 1999;52(3-5):169-172
13 Tonn JC, Westphal M, Rutka JT, Oncology of CNS Tumors. Berlin, Heidelberg: Springer; 2010

14 Patibandla MR, Thotakura AK, Rao MN, et al. Clival giant cell tumor - A rare case report and review of literature with respect to current line of management. Asian J Neurosurg 2017;12(1):78-81

15 El-Mofty SK, Chapter 9 - bone lesions. In: Gnepp DR, ed. Diagnostic Surgical Pathology of the Head and Neck. 2nd ed. Philadelphia: W.B. Saunders; 2009:729-84

16 Khalatbari MR, Hamidi M, Moharamzad Y, Setayesh A, Amirjamshidi A. Brown tumors of the anterior skull base as the initial manifestation of true normocalcemic primary hyperparathyroidism: report of three cases and review of the literature. Turk Neurosurg 2013;23(2):260-266

17 Al-Gahtany M, Cusimano M, Singer W, Bilbao J, Kovacs K, Marotta T. Brown tumors of the skull base. Case report and review of the literature. J Neurosurg 2003;98(2):417-420

$18 \mathrm{Hu} \mathrm{J}$, He S, Yang J, Ye C, Yang X, Xiao J. Management of brown tumor of spine with primary hyperparathyroidism: a case report and literature review. Medicine (Baltimore) 2019;98(14):e15007

19 Leeds N, Seaman WB. Fibrous dysplasia of the skull and its differential diagnosis. A clinical and roentgenographic study of 46 cases. Radiology 1962;78:570-582

20 Parekh SG, Donthineni-Rao R, Ricchetti E, Lackman RD. Fibrous dysplasia. J Am Acad Orthop Surg 2004;12(5):305-313

21 Shen J, Wang S, Zhao X, et al. Skull metastasis from follicular thyroid carcinoma: report of three cases and review of literature. Int J Clin Exp Pathol 2015;8(11):15285-15293

22 Kearns DB, Robinson LD, Wright GL. Wickersham JK, Parke RB Jr. Skull metastases from follicular thyroid carcinoma. Arch Otolaryngol Head Neck Surg 1988;114(4):454-456

23 Gandhoke C, Borde P, Syal S, Singh D, Saran R, Gupta R. Massive skull metastasis from follicular thyroid carcinoma - How ignorance can harm your health. MAMC Journal of Medical Sciences. 2017;3:162-165

24 Gibiezaite S, Ozdemir S, Shuja S, McCook B, Plazarte M, Sheikh-Ali M. Unexpected bone metastases from thyroid cancer. Case Rep Endocrinol 2015;2015:434732

25 D'Antonio C, Passaro A, Gori B, et al. Bone and brain metastasis in lung cancer: recent advances in therapeutic strategies. Ther Adv Med Oncol 2014;6(3):101-114

26 Komatsu T, Kunieda E, Oizumi Y, Tamai Y, Akiba T. Clinical characteristics of brain metastases from lung cancer according to histological type: Pretreatment evaluation and survival following whole-brain radiotherapy. Mol Clin Oncol 2013;1(4):692-698

27 Turner RC, Lucke-Wold BP, Hwang R, Underwood BD. Lung cancer metastasis presenting as a solitary skull mass. J Surg Case Rep 2016;2016(6):rjw116 
28 Hadley C, Gressot LV, Patel AJ, et al. Osteosarcoma of the cranial vault and skull base in pediatric patients. J Neurosurg Pediatr 2014;13(4):380-387

29 Angtuaco EJC, Fassas ABT, Walker R, Sethi R, Barlogie B. Multiple myeloma: clinical review and diagnostic imaging. Radiology 2004;231(1):11-23

30 Kakkar A, Nambirajan A, Suri V, et al. Primary bone tumors of the skull: spectrum of 125 cases, with review of literature. J Neurol Surg B Skull Base 2016;77(4):319-325

31 Rahman A, Bhandari PB, Hoque SU, Wakiluddin ANM. Primary Ewing's sarcoma of the skull. BMJ Case Rep 2013;2013:bcr2012007979

32 Garg A, Ahmad FU, Suri A, et al. Primary Ewing's sarcoma of the occipital bone presenting as hydrocephalus and blindness. Pediatr Neurosurg 2007;43(2):170-173
33 Krishnamani K, Kumar TN, Gandhi LV, Raghunadharao D, Sadashivudu G, Megha U. Primary Ewing's sarcoma of the cranium: case series and review of literature. J Cancer Res Ther 2014;10(2):377-380

34 Desai K, Goel A, Nadkarni TD. Primary petrous bone Ewing's sarcoma. Br J Neurosurg 2000;14(2):143-145

35 Burchill SA. Ewing's sarcoma: diagnostic, prognostic, and therapeutic implications of molecular abnormalities. J Clin Pathol 2003;56(2):96-102

36 Desai KI, Nadkarni TD, Goel A, Muzumdar DP, Naresh KN, Nair CN. Primary Ewing's sarcoma of the cranium. Neurosurgery 2000;46(1):62-68 